\title{
A dinâmica de ocupação e povoamento de Porto Novo: uma colônia étnica e religiosamente homogênea no extremo oeste de Santa Catarina
}

\section{The dynamics of occupation and settlement of Porto Novo: an ethnically and religiously homogeneous colony in the far west of Santa Catarina}

\author{
Leandro Mayer* \\ Rosane Marcia Neumann ${ }^{* *}$
}

Resumo: Este artigo trata do projeto de colonização étnica e confessional de Porto Novo - atual município de Itapiranga-SC -, implantado em 1926 no Extremo Oeste de Santa Catarina, pela Volksverein - Sociedade União Popular. Para manter os princípios do germanismo manteve-se, na execução do projeto, uma homogeneidade étnica alemã e religiosa, pois concentrava significativo número de imigrantes e se tratava de uma colônia católica. Como recorte teórico-metodológico, discute-se a temática sob a perspectiva da história regional e da micro-história.

Palavras- chave: Colonização, Porto Novo, germanismo, católicos.

Abstract: This article deals with ethnic and confessional colonization project of Porto Novo - current municipality of Itapiranga-SC - established in 1926 in the Far West of Santa Catarina, by Volksverein - Popular Union Society. For keeping the principles of germanism remained, in the implementation of the project, an ethnic and religious german homogeneity, because there was a significant number of immigrants and it was a Catholic colony. As a theoretical and methodological approach, the theme is discussed from the perspective of regional history and microhistory.

Keywords: Colonization; Porto Novo; germanism; catholics

\section{Considerações iniciais}

$\mathrm{O}$ artigo apresenta resultados preliminares do estudo sobre o projeto de colonização Porto Novo, cujas origens remontam ao ano de 1926. A colonização foi planejada, organizada e promovida pela Volksverein für die Deutschen Katholiken in

\footnotetext{
* Mestrando do Programa de Pós-Graduação em História da UPF. Bolsista CAPES..

** Doutora em História - PUCRS. Professora do Programa de Pós-Graduação em História da UPF.
} 
Revista Brasileira de História \& Ciências Sociais - RBHCS

Vol. $8 \mathrm{~N}^{\mathrm{o}}$ 16, Julho - Dezembro de 2016

Rio Grande do Sul - Sociedade União Popular para Alemães Católicos no Rio Grande do Sul (SUP). Entre os colonos, era conhecida simplesmente como Volksverein.

A SUP foi criada em 1912, durante o Congresso de alemães católicos, em Venâncio Aires ${ }^{1}$, e seu idealizador foi o padre Jesuíta Theodor Amstad S.J.. Trata-se de uma dissidência da Riograndenser Bauernverein (Associação Rio-grandense de Agricultores), associação criada em 1900, e que agregava alemães católicos e protestantes. A partir de então, cada grupo religioso passou a contar com a sua associação.

A formação da SUP e a implementação do projeto de colonização de Porto Novo, segundo Eidt (2011), foi uma resposta concreta do novo modelo eclesial, tão desejado pela igreja romana do século XIX. Rohde (2011) explica que a SUP (Sociedade União Popular) visava atender as demandas materiais, espirituais e culturais de seus associados, cujo número chegou a 12 mil alemães no final da década de 30, antes do início da ${ }^{\mathrm{a}}$ Guerra Mundial. Sobre a Volksverein, Klauck (2014, p. 143) salienta que "a essência dos objetivos dessa associação resume-se em organizar os católicos de ascendência alemã em torno de uma sociedade que preconizasse o seu bem-estar social, material e religioso”. Referindo-se a entidade, Gertz (1991, p. 38) afirma ser "a expressão mais importante de instituição católica ligada ao trabalho com os católicos de origem alemã e de preservação de sua identidade. E essa organização está desde o início sob o controle dos jesuítas e de pessoas ligadas a eles”. Tinha por objetivo um projeto de desenvolvimento econômico e de promoção humana (RAMBO, 2011).

Note-se que todos os projetos de colonização públicos e privados do século XIX até meados do século XX, apresentam perfis semelhantes. Todavia, cada qual tem as suas especificidades, que fogem à percepção das grandes análises históricas. Partindo desse pressuposto, optou-se em termos teórico-metodológicos pela redução da escala de análise, método que sugere "ver o particular, não para falar do local, mas para encontrar perguntas gerais que permitam realizar infinitas constatações. Então, partimos do particular" (LEVI, 2014, p. 247). Sob essa perspectiva, "estudamos coisas

1 "O tema central escolhido para o Congresso foi a situação cultural, educacional, religiosa e econômica das comunidades católicas teutas. Chegara-se a um ponto em que se tornara inadiável realizar um diagnóstico realista da situação, identificar os principais problemas, partir para um ambicioso projeto de promoção humana de médio e longo prazos, apostar em soluções e escolher os meios e as estratégias de ação eficientes" (RAMBO, 2011, p. 234-235). Outras informações sobre a Sociedade União Popular, entre elas, o esboço de estatuto, organização e funcionamento, podem ser lidos no livro Somando Forças - o projeto social dos Jesuítas no sul do Brasil, de Arthur Blásio Rambo (2011). 
grandes com o microscópio. Buscamos saber quantas coisas importantes acontecem quando aparentemente não acontece nada” (LEVI, 2014, p. 247). A análise e o estudo do particular dão a possibilidade de identificar as diferenças e não as semelhanças. Nesse contexto, no particular identificamos a origem de processos que são analisados apenas na ótica global, a qual ignora as particularidades. Contudo, é necessário "tomar o cuidado de não transferir automaticamente para o âmbito macroscópico os resultados obtidos num âmbito microscópico, e vice versa (ACIOLI, 2012, p. 6), ou seja, não se devem considerar como conclusões definitivas os resultados que poderiam ser relativizados. Nestes termos, a micro história compreende uma mudança na escala de observação do plano "macro" para o "micro", surgindo como resposta ao modelo generalizante (macroscópico e quantitativo) que dominou a cena historiográfica internacional por várias décadas no século XX (GINZBURG, 2007).

\section{A fundação da Colônia Porto Novo: uma organização coletiva teuto católica}

Conforme Neumann (2014), os projetos de colonização étnica eram bem vistos "pela ala germanista" do estado do Rio Grande do Sul, enquanto projetos de colonização mistos eram criticados pela "despreocupação com questões étnicas e confessionais”. A fundação da colônia Porto Novo está associada ao desejo de fundação de um núcleo que possibilitasse a reprodução étnico-confessional. A intenção inicial era fundar essa nova colônia no Rio Grande do Sul, porém, o governo daquele estado não autorizou a instalação de uma colonização cujo princípio de ocupação fosse a homogeneidade étnica e religiosa, como pretendiam os dirigentes da Volksverein. Roche (1969) considera que a política adotada pelo governo do Rio Grande do Sul de não permitir novas colonizações nas últimas terras devolutas, impulsionou a emigração de colonos rio-grandenses: "em lugar de distribuí-las imediatamente, como lhe aconselhavam, preferiu proteger as últimas reservas florestais. Para não perdê-los todos nas gerações seguintes, preferiu deixar partir uma fração de colonos rio-grandenses" (ROCHE, 1969, p. 359-360). O padre Jesuíta Luiz Heinen (1997) atribui à Maçonaria, o Positivismo e as consequências da Primeira 
Guerra, como fatores determinantes para que o governo do estado do Rio Grande do Sul não autorizasse o núcleo de colonização pretendido pela Volksverein. A partir daí, buscou-se o estado vizinho, Santa Catarina, para a implantação do projeto de colonização.

A decisão de fundar o Projeto Porto Novo foi tomada na reunião dos delegados das Caixas Rurais em 26 e 27 de abril de 1925 (JUNGBLUT, 2000). Meses depois, em 28 de janeiro de 1926, ocorreu a primeira compra de terras adquiridas por força de contrato, compondo 100 lotes, no extremo oeste de Santa Catarina. "A compra foi acertada após longas negociações. As terras ofereciam uma vantagem rara no sul do Brasil” (RABUSKE; RAMBO, 2004, p. 59). Em contrapartida,

era de interesse do governo catarinense em promover a ocupação daquele espaço, já contestado algumas vezes ao longo da história. Além disso, a empresa Colonizadora Chapecó-Pepery, detentora das terras no Alto Vale do Rio Uruguai e que já havia promovida a colonização de Porto Feliz - atualmente o município de Mondaí enfrentava grave crise econômica, assim, a Volksverein aproveitou a oportunidade para adquirir uma faixa de terras as margens do Rio Uruguai na fronteira com a Argentina (FRANZEN, 2014, p. 82).

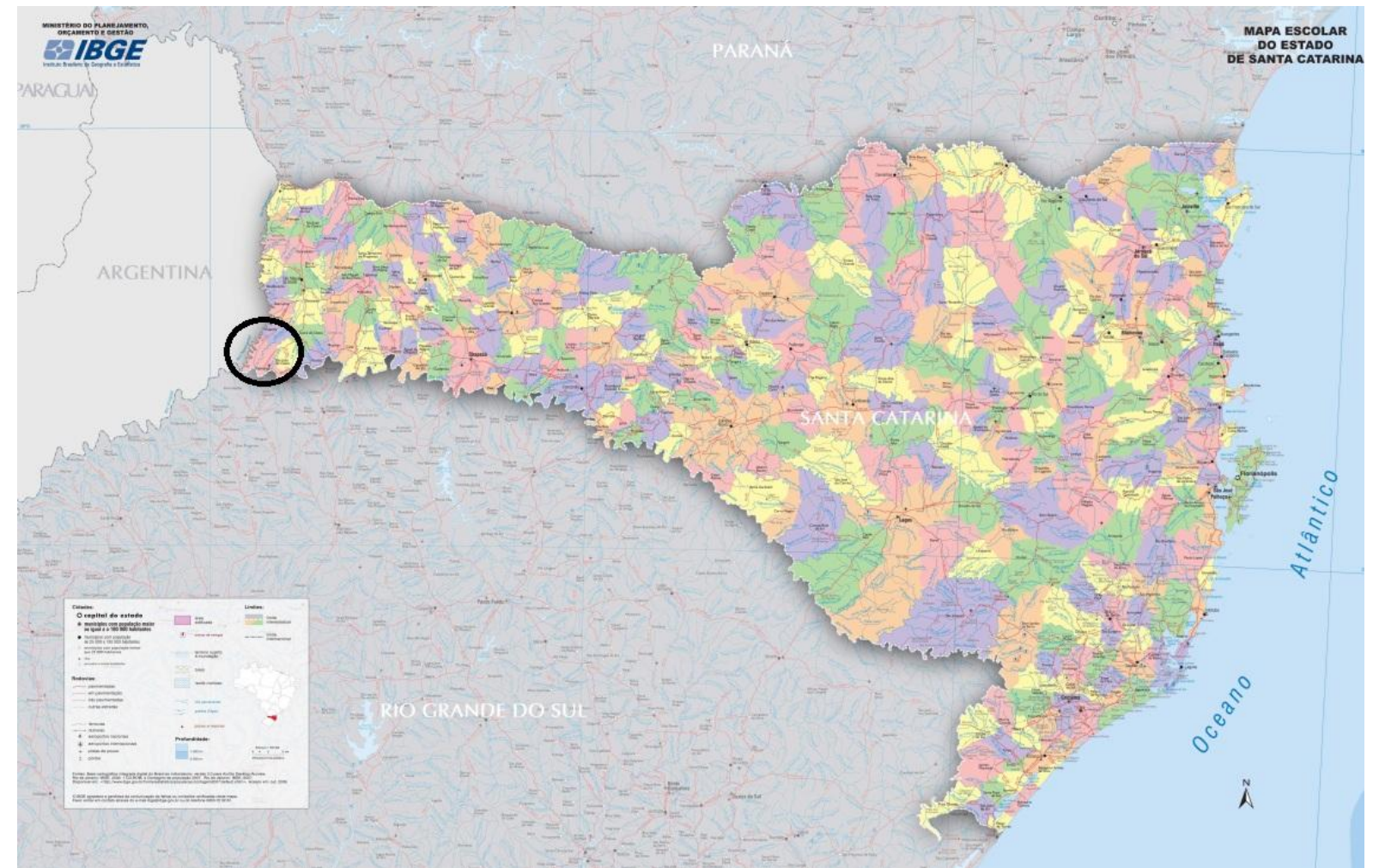

Figura 1 - Mapa de Santa Catarina. Em destaque localização do atual município de Itapiranga região que a partir de 1926 recebeu o projeto de colonização Porto Novo. Fonte: http://www.infoescola.com/wp-content/uploads/2009/12/mapa-sc-municipios.jpg 
A colônia Porto Novo, como podemos observar no mapa, situa-se numa região de fronteira: com o Rio Grande do Sul - onde a divisa é dada pelo Rio Uruguai; e com a Argentina - cuja divisa ocorre pelo Rio Peperi Guaçú ${ }^{2}$ O projeto de colonização Porto Novo torna-se "o primeiro prolongamento da colonização teuto-brasileira católica do Rio Grande do Sul em Santa Catarina” (HEINEN, 1997, p. 71). Quanto ao espaço geográfico onde o projeto de colonização Porto Novo foi implantado, suas terras até então eram consideradas devolutas 3 .

O espaço geográfico, oficialmente considerado devoluto, pertencia à Empresa Pepery Ltda e, anteriormente, à multinacional Brasil Development and Colonization Company, filial da empresa inglesa Railway Company, que recebeu grande parte do território do oeste catarinense como pagamento pela construção de uma ferrovia, ligando o Rio Grande do Sul a São Paulo, na primeira década do século XX. Parte desse território foi adquirido por uma das instituições que servia de ponto de convergência para qualquer consecução de atividades coletivas nas denominadas colônias velhas, a Volksverein (Sociedade União Popular - SUP). (EIDT, 1999, p. 16).

As terras do Oeste do estado de Santa Catarina ficaram conhecidas "nas primeiras décadas do século XX, como 'terra sem lei’, sem dono e 'sertão bruto', em razão do seu processo histórico de abandono, permeado por disputas e lutas internacionais e nacionais" (NODARI, 2009, p. 23). Sobre essas disputas, podemos citar a "Questão de Palmas ou Missiones"4 - conflito que envolveu o Brasil e a Argentina entre os anos 1857 a 1895, decorrente da divisão territorial, cujo território em litígio é hoje representado por parte do Oeste catarinense e o Sudoeste paranaense; e o Conflito do Contestado (1912 - 1916) 5 - envolvendo os estados de Santa Catarina e Paraná num conflito desencadeado para definição dos limites dos dois estados.

\footnotetext{
${ }^{2}$ Como se pode perceber pelo mapa, a região de abrangência da colônia Porto Novo é delimitada por duas fronteiras importantes: ao Sul com o estado do Rio Grande do Sul, e, a Oeste com a Argentina. Esta situação de fronteira foi palco de cenas muito conturbadas durante o período do Estado Novo, com a repressão aos alemães, visto que, nesta colônia de ocupação alemã, numa zona de fronteira, estava localizado um povoamento homogêneo de alemães católicos. Além do mais, a proximidade com a fronteira Argentina se tornaria outro agravante. Poderiam ser estes colonos ali estabelecidos uma ameaça à segurança nacional?

3 Para Nodari, o conceito de terras devolutas, para o Estado, implica considerá-las desabitadas, sem registro de propriedade, apesar de muitas dessas terras serem ocupadas por posseiros (NODARI, 2009, p. 30).

4 Ver HEINSFELD, Adelar. A questão de Palmas entre Brasil e Argentina e o início da colonização alemã no baixo vale do rio do Peixe. Joaçaba: UNOESC, 1996.

5 Ver HEINEN, Luiz. Colonização e Desenvolvimento do Oeste de Santa Catarina: Aspectos SócioPolíticos-Econômicos e Religiosos. Joaçaba: UNOESC, 1997.
} 
Revista Brasileira de História \& Ciências Sociais - RBHCS

Vol. $8 \mathrm{~N}^{\mathrm{o}}$ 16, Julho - Dezembro de 2016

Nodari salienta que a grande região oeste do estado de Santa Catarina tinha impregnado um sentimento de abandono, sem uma política de ocupação efetiva por parte do Estado até o início do século XX.

O conhecimento da história da ocupação populacional do Oeste catarinense ajuda a entender esse sentimento de abandono que a historiografia registrou, por parte dos habitantes. Diferentemente de outros locais como o Vale do Itajaí e o Sul do estado de Santa Catarina, não houve por parte das autoridades governamentais uma política de ocupação efetiva até o início do século XX (NODARI, 2009, p. 24).

Após a efetivação da primeira compra de 100 lotes coloniais pela Volksverein, novos lotes foram comprados, chegando-se ao total de 583.975.705,40 metros quadrados de área (o equivalente a 58.397 hectares), que foram divididos em 2.340 lotes coloniais, cada qual com 25 hectares em média, tornando-se esta a delimitação territorial da colônia. O projeto de colonização Porto Novo se diferenciava de qualquer outra colonização, pelo modelo de separação étnico e confessional que fora adotado.

As colonizações promovidas por empresas particulares e de modo especial pelos governos municipais e estadual, orientavam-se pelo princípio da integração étnica e confessional, ou melhor dito, pela mistura racial e confessional. A colonização de Porto Novo, pelo contrário, adotou o modelo da separação étnica e confessional. Tratava-se, portanto, de assentamentos à base da mesma procedência étnica e adeptos da mesma confissão religiosa (RAMBO, 2011, p. 264).

Projetos de colonização étnico-confessionais não foram tão comuns ao longo do processo de imigração e colonização no Brasil no século XIX até meados do XX. Em razão disso, o caso de Porto Novo sobressai como um modelo excepcional normal (GRENDI, 1998), inserido em um contexto republicano catarinense, quando o discurso oficial preconizava a colonização mista.

\section{A intensificação de propagandas e a ocupação de Porto Novo}

Uma vez efetuada a aquisição de terras, a campanha publicitária sobre Porto Novo foi desencadeada, "sendo que o Katolikentag 6 - Congresso dos Alemães

\footnotetext{
${ }^{6}$ Eram Congressos Rurais Católicos. Sobre eles, temos a contribuição de Heinen: ""Katholikentage", literalmente "Dias dos Católicos". Eram 3 dias de encontros festivos das lideranças rurais teutas do Estado do Sul, com celebrações religiosas, sessões teatrais e culturais à noite. Durante os 3 dias,
} 
Católicos do Rio Grande do Sul, realizado em Novo Hamburgo de 14 a 16 de março de 1926, foi o momento escolhido para o lançamento publicitário do projeto” (JUNGBLUT, 2000, p. 75). A entidade Volksverein iniciou, a partir de então, a veiculação de propagandas sobre o novo empreendimento colonizador. Para isso, fez uso de seu principal meio de comunicação com os associados: a revista Skt Paulusblatt7. Os anúncios do empreendimento eram inicialmente convites para interessados conhecer o projeto, conforme segue:

Viagem para conhecer as terras de Porto Novo e Porto Feliz. Depois da Páscoa realizarei uma viagem, como guia autorizado de um grupo numeroso de colonos católicos e evangélicos interessados em comprar terras nas áreas de Porto Novo e Porto Feliz, respectivamente. Aqueles que ainda querem se integrar ao grupo, deverão estar no Hotel Müller, em Santa Maria, o mais tardar sábado, dia 10 de abril. A longa viagem será iniciada na manhã seguinte. Trazer o poncho. C. F. Rohde - Estrela (apud ROHDE, 2011, p. 30).

No anúncio publicado, percebemos que menos de três meses após a consolidação da negociação das terras pela Volksverein, as primeiras comitivas de “compradores alemães" visitavam Porto Novo, cujas terras eram prometidas como muito férteis. Nos meses subsequentes, os anúncios na Skt Paulusblatt e no jornal Folha Popular Alemã (Deutsches Volksblatt) se intensificaram. As propagandas se difundiram nas colônias velhas do Rio Grande do Sul, cujas terras estavam escassas e subdivididas. Em seu estudo, Roche (1969) revela que os primeiros lotes coloniais destinados aos colonos imigrantes no início do século XIX, mediam em média 77 hectares. Posteriormente, como no município de Estrela, "as primeiras propriedades, vendidas a partir de 1853, mediam, em média, 48 hectares. Em 1920, a divisão estava

palestras e debates sobre todos os assuntos que interessavam e preocupavam a população local: vida, família, educação dos filhos, escola, alimentação, saúde, lazer, leitura, melhoria no trabalho agrícola e pecuário, novas técnicas agrícolas, conservação e recuperação do solo, esterqueiras, adubo verde, sementes de soja, etc. E tudo isso na virada do século, um trabalho pioneiro" (HEINEN, 1997, p. 71).

7 Revista teuta Sankt. Paulusblatt - periódico redigido e publicado mensalmente pela Volksverein. Trazia matérias de leitura como lições de economia rural, orientações espirituais e educação cívica. Ainda sobre a revista Paulusblatt, Klauck afirma: "Pode-se definir a revista como um dos instrumentos utilizados pelo catolicismo da imigração implantado pelos jesuítas entre os alemães e descendentes, desde a última metade do século XIX (LUTTERBECK, 1977; SILVA, 2003; SCHALLENBERGER, 2001; RAMBO, 2002), para acompanhar e ordenar os espaços sociais do segmento católico, integrantes desse contingente populacional. E, nesse contexto, os jesuítas também podem ser compreendidos como instrumentos da Igreja na organização prática do campo associativo e político. Pois, entre 1890 e 1912, esses, de forma direta, contribuíram para a fundação de seis associações: 1890, o Centro Católico; 1890, as Associações Paroquiais ou Pfarrvereine; 1898, os Congressos Católicos ou Katholikentage; 1898, a Associação de Professores ou Lehrerverein; 1890, a Associação de Agricultores ou Bauerverein; e, 1912, a Sociedade União Popular ou o Volksverein (RABUSKE, 1994/1996, p. 29)" (KLAUCK, 2014, p. 142). 
já muito avançada, porquanto a superfície média era de apenas 24,2 hectares. Em 1950, desceu para 15,7 hectares, nem mesmo o terço da primitiva área" (ROCHE, 1969, p. 325-326). Esta problemática está diretamente associada com o crescimento demográfico, e a alternativa das famílias era a subdivisão das propriedades, embora, "subdividir as propriedades uma ou duas vezes significava condenar à miséria as famílias que delas dependiam" (RAMBO, 2011, p. 175). Esses fatores impulsionaram os descendentes de imigrantes migrarem em busca de novas regiões de colonização, favorecendo para que muitos colonos, em sua maioria jovens, buscassem a nova colônia em formação, que a essa altura tinha a garantia de ser uma terra muito promissora para o desenvolvimento da agricultura. Além da promessa de encontrar terras férteis para a agricultura, o preço dos lotes era um atrativo à parte, se comparado aos preços praticados no Rio Grande do Sul no mesmo período.

Nos anos iniciais do projeto de colonização, o acesso à colônia era possível apenas pelo Rio Uruguai - de Porto Feliz (hoje Mondaí) a Porto Novo. Até Porto Feliz havia estrada. $\mathrm{O}$ abastecimento da colônia com gêneros e mantimentos também ocorria por este meio, o que causava um sentimento de isolamento. Rambo (2011) considera a decisão de migrar das colônias velhas à Porto Novo uma "ruptura", comparável até mesmo à emigração da Alemanha ao Brasil:

Partir para uma frente de colonização distante mais de quatrocentos quilômetros, implicava um rompimento praticamente total e definitivo, fato que assustava não poucos. Nessa situação, somente pessoas mais afoitas, mais empreendedoras e, quem sabe, em situação muito difícil, dispunha-se a enfrentar uma ruptura, comparável àquela que seus pais ou avós assumiram ao emigrarem para o Brasil (RAMBO, 2011, p. 286).

Embora a teoria do isolamento seja contestada pela comunidade acadêmica (cf. TRAMONTINI, 2003; WITT, 2008), era esse o sentimento descrito em diversos autores sobre os primeiros anos de colonização de Porto Novo. Não nos referimos aqui ao "isolamento cultural" (GERTZ, 1991), mas falamos das dificuldades de comunicação dos moradores da colônia com outras regiões e pelo acesso limitado, visto que a colônia se localizava em meio à mata, o que levou alguns a pensar em desistir e voltar ao seu local de origem, mas, a carência financeira os obrigou a ficar.

\section{A homogeneidade étnica e religiosa}


Para ter direito à posse de terras em Porto Novo, o comprador de lotes deveria ser de origem alemã e católica. Com essas exigências, pretendia-se formar uma colônia étnica e religiosamente homogênea, com famílias católicas e alemãs. "Os migrantes recrutados deveriam enquadrar-se nos requisitos que a Igreja Católica impunha para a vanguarda dos benefícios espirituais e cuidados culturais, além da socialização das oportunidades de trabalho" (EIDT, 1999, p. 9).

Essa preocupação quanto ao caráter normativo da colonização percebe-se nas palavras de Beschlüsse, líder comunitário em fala proferida na assembleia do Katholikentag em Serro Azul em 1928: “a assembleia geral adverte os colonos a escolher as colônias católicas para novas colonizações, pois como a experiência sempre nos ensinou, as colônias separadas religiosa e linguisticamente são a garantia da manutenção da nossa religião, costumes e tradições” (BESCHLÜSSE apud WERLE, 2011, p. 170).

Dentre os maiores críticos, estavam os jesuítas católicos, envolvidos diretamente na assistência religiosa da zona colonial alemã e italiana, ligados ao Bauernverein e Volksverein. Defenderam abertamente a colonização confessional e étnica, tendo como seus expoentes os padres jesuítas Theodor Amstad, João Evangelista Rick, Max von Lassberg. De acordo com Amstad,

a mistura étnica e confessional se constitui num dos grandes males das atuais colonizações do governo [republicano]. Em não poucos casos, põe-se em prática uma ação planejada nesse sentido, visando, como se diz, a estimular a formação de "um tipo brasileiro uniforme". Como consequência desse sistema, os elementos melhores e mais bem dotados abandonam as "colônias misturadas" e vão fixar-se em colônias de associações nas quais se pratica a colonização étnica e confessionalmente identificada (Cem anos de germanidade..., 1999, p. 51).

Aliás, na avaliação do padre jesuíta Balduíno Rambo,

não demorou para ficar claro que era preciso separar não só por confissões como também por nacionalidades. As colônias mistas de alemães, italianos e poloneses não logravam organizar uma vida comunitária como era de desejar. Em muitos casos o segmento mais fraco migrava para outro lugar, fato que criava também sérios obstáculos para o desenvolvimento econômico (RAMBO apud RAMBO e RABUSKE, 2004, p. 58).

É possível denotar que o foco era formar uma colonização homogênea em termos linguísticos e religiosos, diferente do modelo de colonização que ocorreu em outras regiões de Santa Catarina, onde os lotes de terra eram comercializados a 
Revista Brasileira de História \& Ciências Sociais - RBHCS

Vol. $8 \mathrm{~N}^{\mathrm{o}}$ 16, Julho - Dezembro de 2016

"qualquer interessado", visto que o modelo era "comercial". Neste sentido, o projeto de colonização estabelecido em Porto Novo se distinguiu de todos os outros modelos. Conforme Middeldorf, a colonização Porto Novo foi idealizada sob os seguintes preceitos:

A colonização de Porto Novo não é um empreendimento comercial. Não visa a especulação financeira e segue unicamente o programa de colonização. A Volksverein persegue objetivos colonizatórios, econômicos e culturais. A serviço da religião e da boa identidade do povo, visa colonizar as terras com agricultores católicos e de fala alemã (MIDDELDORF apud WERLE, 2011, p. 175).

Gradativamente a homogeneidade étnica e confessional do núcleo se tornava realidade. Considerável progresso e procura por lotes de terras foram registrados nos primeiros anos. Apesar das dificuldades iniciais de implantar um modelo colonizador em meio a mata densa e virgem, sem nenhuma estrutura de acesso, como estradas, por exemplo, o autor considera que certamente o espírito solidário e comunitário foi essencial para que o modelo prosperasse.

Sobre a religiosidade da "comunidade orante de Porto Novo", Jaeger afirma que

o povo, nesses tempos, era simples, sem luxo e não pensava em desfrutar conforto. Dava-se muito valor a participação da santa missa aos domingos. Na igreja matriz, aos domingos, havia duas missas: uma pelas 7:30 h, e outra, pelas 10:00 h, sempre com igreja repleta. $\mathrm{O}$ pessoal vinha de longe (6 a $8 \mathrm{~km}$ ), a cavalo e a pé. Quando tinha barro, traziam os sapatos ou chinelos na mão e caminhavam "de pé no chão". Chegando à sede, lavavam os pés e calçavam os sapatos. Ao bater o sino de manhã, nas "Ave Marias", o sacristão abria a igreja, onde já havia gente esperando para confissão (JAEGER, 1998, p. 22).

Embora houvesse toda esta preocupação em formar uma comunidade ideal, logo nos primeiros anos, alguns problemas foram verificados. O relatório anual de 1931, referente às atividades da paróquia, sugere-nos que havia algumas divergências entre os moradores recém chegados à nova colônia, conforme podemos ler no livro de registros da paróquia:

Como aqui ainda é colônia nova e vem entrando sempre novos moradores de todas as partes, cada qual traz o seu modo de parecer e querer que aqui também se faça como se tem feito na terra donde elle tem chegado, já se vê que isso é impossível, e dali as difficuldades uns querem assim outros assim alguns não querem ajudar nada nem na igreja, capella nem aula; dessas desavensas e diversos pareceres resulta que é preciso uma firme e determinada organização á qual 
todos se devem sujeitar. Foi esse o principal trabalho para o anno 1931 e em parte se tem conseguido ainda não de todo porem em grande parte (LIVRO TOMBO, 1931, p. 06).

Uma destas falas do Livro Tombo ${ }^{8}$ nos é muito oportuno aprofundar: "é preciso uma firme e determinada organização à qual todos se devem sujeitar". Quem toma a frente nas "firmes decisões" que são frisadas pelo religioso que fez estas anotações no livro de registros? Será que eram lideranças em meio aos colonos? Administradores do projeto Porto Novo? Ou será que estas decisões eram do clero? Quem fomentava estes discursos de unidade étnica e religiosa, e, porque não dizer "ideológicos"? Fica cada vez mais evidente que, para se enquadrar no projeto Porto Novo, era necessário ter certo perfil estabelecido pelas "relações de poder local" - o que nos leva a crer que era a igreja - como "ideal". Todos deveriam se enquadrar e sujeitar à organização estabelecida. Ou se adaptaria, ou... se adaptaria!

Numa análise mais criteriosa, verificamos que, o que há em Porto Novo, é a instituição de valores, estes, socialmente aceitos pelos seus moradores diante do olhar atento do clero, o que, conforme a autora, é capaz de gerar comportamentos imobilizadores aos indivíduos que ao grupo participam, conferindo a este, uma identidade própria:

Quando a gente ia na igreja no domingo de manhã, era como se toda a comunidade fosse uma só família. [...] Naquela época a comunidade era uma família. Quando a gente estava na Igreja nós éramos uma só coisa, como uma só família". O primeiro compromisso no domingo era com a Igreja, mas à tarde estavam livres para escolher o que fazer (JORNAL EXPRESSÃO, 2012, ed. 337, p. 24).

Anotações da visita pastoral9 realizada de 29 de novembro a 8 de dezembro de 1935, que consta no Livro Tombo da paróquia São Pedro Canísio de Itapiranga, traz a seguinte revelação:

É esta parochia ainda nova, formada de colonos catholicos de origem allemã vindos em sua grande maioria do Rio Grande Do Sul. Poucos os que vieram diretamente da Europa, estabelecendo-se logo aqui! há ainda nesta região que se vai colonizando extensas mattas virgens de terras fertilíssimas. Ainda poucas terras que o braço calorioso do colono amanhou ou antes começou amanhar. - Apesar da distancia

\footnotetext{
8 É necessário atentar que, neste ano (1931) a paróquia é assumida pelos padres Jesuítas.

9 As visitas pastorais ocorriam geralmente a cada dois anos. Na oportunidade, o Bispo visitava as Paróquias e Capelas de sua Diocese. As primeiras visitas à Paróquia São Pedro Canísio foram feitas pelo Bispo Prelado de Palmas, a cuja Diocese a Paróquia esteve ligada até 1958, quando foi criada a Diocese de Chapecó.
} 
em que transita a via férrea, prevê-se que em breve futuro esta região prosperará sempre mais e crescerá não pouco o número de seus habitantes que se irão internando pelas florestas adentro (LIVRO TOMBO, 1935, p. o9).

A anotação segue com a seguinte fala: "notamos com satisfação que o povo, sob a dedicada e esclarecida direcção dos Padres da Companhia de Jesus, é em geral crente, piedoso e praticante da religião" (LIVRO TOMBO, 1935, p. 9). As expressões que classificam o povo de Itapiranga como crente, piedoso e praticante da religião, certamente expressam a alegria e entusiasmo dos religiosos em relação à colonização formada, uma comunidade de orantes, proteladores da fé cristã. Quanto à dedicada e esclarecida direção dos padres da Companhia de Jesus, é a prática dos princípios dos Estatutos Sociais Católicos da Itália, que eram diretrizes do pensamento social do Papa Leão XIII, cujas bases do pensamento serviram de modelo para a Sociedade União Popular (ROHDE, 2011, p. 22), onde entre eles, encontramos o de "concentrar todos os esforços dos católicos do país para o mesmo objetivo: defesa, manutenção e desenvolvimento da fé e modo de vida católico [...] Divisão territorial do país em associações diocesanas e sociedades locais." (ROHDE, 2011, p. 22). Quando este fala em defesa, manutenção, desenvolvimento da fé e modo de vida católico, e divisão territorial do país em sociedades locais, acreditamos que estes tenham sido os princípios almejados pelos Jesuítas em Porto Novo, onde, numa organização fechada para alemães católicos, formou-se a sociedade local.

Outras anotações de visita pastoral realizada de 23 a 28 de abril de 1937, sustentam todas as hipóteses levantadas anteriormente, e, mais uma vez, refere-se ao povo de Porto Novo, como compenetrado da sua fé católica e cumpridor dos deveres religiosos, enaltecendo a educação cristã ministrada à infância e juventude, conforme lemos:

Encontrámos aqui um povo compenetrado da sua fé catholica e cumpridor dos deveres religiosos. A [...] da população em pezo, - de crianças, jovens, senhoras e homens, - aos santos sacramentos e à $\mathrm{S}$. missa, em todos os dias, foi a prova evidente do espirito de catholicidade que aqui domina e da educação christã ministrada à infância e juventude. É esta a nossa grande, e maxima satisfação; que pedimos a Deus queira conservar perpetuamente nos corações dos moradores daqui (LIVRO TOMBO, 1937, p. 11). 
A anotação traz outra informação importante, relacionada à ordem e disciplina dos moradores da paróquia: "Muito nos impressiona a ordem e disciplina do povo em todas as manifestações e encontros que tivemos" (LIVRO TOMBO, 1937, p. 12).

A presença da igreja era muito forte nas comunidades. Ademais, no isolamento da vida pioneira, sem a presença efetiva do Estado, a população via na igreja, especialmente na figura do padre, a autoridade, a lei, a verdade. Mensalmente o padre visitava cada uma das comunidades, em visitas que duravam um ou dois dias, dependendo do tamanho da comunidade. Sobre essas visitas, Heinen esclarece:

Cada visita à capela era super-organizada e cronometrada em seus pormenores, nas 23 horas de permanência do padre na Comunidade. Também quando a visita era de 2 dias, nas comunidades maiores.

A chegada do padre acontecia pelas 14 horas. Havia alguém encarregado de tomar conta da montaria, desde a chegada até à partida.

De tarde havia catequese para os alunos da escola, depois confissões para quem desejasse. Confissões depois da janta e de madrugada, à luz de "aladim". A missa cedinho, com uma hora de claridade. Após o café, encontro com a diretoria e algum assunto particular, até perto do almoço. Partida pelas 13 horas para a capela seguinte. Na visita de 2 dias, um deles geralmente era domingo, com duas missas, benção do Santíssimo Sacramento, Visita aos doentes da Comunidade (HEINEN, 1997, p. 151).

A Colônia Porto Novo se tornava referência para a Volksverein e era com frequência estampada em propagandas, especialmente na revista 'Skt. Paulusblatt'. Excerto do relatório anual do Skt. Paulusblatt - 1930 faz referência à promissora colônia: “Os números provam, aos leitores, que a evolução do empreendimento, está além do esperado [...] que Porto Novo se tornasse o que é hoje: uma colonização modelar, com um futuro promissor” (apud ROHDE, 2011, p. 153). Para a autora, o progresso segue nos anos subsequentes, e a colônia Porto Novo representa um empreendimento exitoso, nunca antes visto entre os sistemas de colonização. Para a Volksverein, significava a realização de um ideal. Em 1938, Porto Novo contava com mais de 6 mil habitantes, distribuídos em 17 comunidades (ROHDE, 2011).

A homogeneidade, especialmente aquela de caráter religioso, vista por Eidt como "sonho cristão", pautava-se nos valores religiosos prescritos pela igreja, num conjunto de prerrogativas assimiladas pelos moradores de Porto Novo desde o início de sua colonização. "A Igreja se constituía numa unidade poderosa em torno da qual tudo se ramificava. Nas desavenças entre os migrantes pioneiros, o clero arrogava-se o direito de estabelecer a verdade” (EIDT, 2011, p. 25). E conclui: 
No isolamento da vida pioneira, a transmissão de saberes passava pela linhagem familiar ou pela instituição escola/Igreja. Sem parâmetros exógenos, as instâncias da família, escola e religião transmitiram os valores e os ideais da cultura. Assim, o mundo, limitado e restrito, limitou possibilidades e serviu como ponto de estrangulamento, gerações inteiras foram vítimas do silêncio e do debate impermeável (EIDT, 2011, p. 22-23).

Em relação à manutenção da prática religiosa e a valorização do sentimento religioso pelas companhias colonizadoras, Nodari argumenta que:

\begin{abstract}
Muitas companhias sabiam que o atendimento religioso na comunidade era importante para a manutenção das práticas socioculturais e, no Rio Grande do Sul, já contavam com a presença regular de padres e pastores. Dessa forma, a valorização do sentimento religioso passou a fazer parte da propaganda das colonizadoras (NODARI, 2009, p. 45).
\end{abstract}

Assim se justifica a formação homogênea de Porto Novo em torno dos quesitos religiosos e étnicos, sendo que estas, para Nodari, foram uma maneira interessante para atrair pessoas que pretendem conviver com indivíduos do mesmo credo ou etnia, mantendo suas práticas sócio culturais, "definindo, assim, num primeiro momento, uma cultura étnica que gerava solidariedades no seu interior e que os mantinha distantes de tensões internas e externas” (NODARI, 2009, p. 47). A homogeneidade religiosa era defendida pelos religiosos, entre eles, o Pe. Lassberg, o qual "era insistente toda vez que falava de colonizações argumentando que a convivência entre protestantes e católicos deveria ser amistosa, mas que os evangélicos deveriam morar numa picada e os católicos numa outra" (JUNGBLUT, 2015, p. 71).

\title{
Considerações finais
}

Apesar de o estudo apresentar resultados preliminares, concluímos que o projeto de colonização Porto Novo foi um modelo que se diferenciou da maior parte dos projetos de colonização desenvolvidos pela iniciativa pública e privada no estado de Santa Catarina e até mesmo no Rio Grande do Sul. Porto Novo constituiu-se de um projeto de iniciativa privada, executado pela Volksverein - Sociedade União Popular que teve na coordenação dos trabalhos os padres Jesuítas. Implantado no Extremo Oeste de Santa Catarina, teve a homogeneidade étnica e religiosa como diferenciais, formando assim, uma colonização étnica alemã, concentrando (i)migrantes católicos 
num núcleo relativamente fechado em si mesmo, alicerçado nos princípios de germanismo.

A maior parte dos imigrantes que se estabeleceram a partir de 1926 em Porto Novo são oriundos das colônias velhas do Rio Grande do Sul, onde naquela época era registrada grande escassez de terras em consequência do crescimento demográfico, o que impulsionou especialmente os mais jovens, a busca por novas frentes de colonização. Neste contexto, a colônia Porto Novo figurava como terra promissora para o desenvolvimento da agricultura e para a manutenção da fé católica, atraindo até o ano 1938 mais de 6 mil (i)migrantes.

\section{Referências bibliográficas}

ACIOLI, Caroline. O Comedor de Jia: uma experiência de micro-história sergipana?. In: Anais Eletrônicos do IV Seminário Nacional Literatura e Cultura São Cristóvão/SE: GELIC/UFS, V. 4, 3 e 4 de maio de 2012.

Cem anos de germanidade no Rio Grande do Sul 1824-1924. São Leopoldo: UNISINOS, 1999.

EIDT, Paulino. SILVA, Edinaldo Enoque. Porto Novo: do reino religioso ao poder de mercado. Curitiba: CRV, 2011.

Porto Novo: da escola paroquial ao projeto de nucleação - uma identidade em crise. Ijuí: Editora da Unijuí, 1999.

GERTZ, René E. O perigo alemão. Porto Alegre: UFRGS, 1991.

GINZBURG, Carlo. Sinais: raízes de um paradigma indiciário. In: . Mitos, Emblemas, Sinais. 2. ed. São Paulo: Companhia das Letras, 2007, p. 143-179.

GRENDI, Edoardo. Repensar a Micro-História. In: REVEL, Jacques (org.). Jogos de Escalas: a experiência da micro-análise. Rio de Janeiro: FGV, 1998, p. 251-262.

HEINEN, Luiz. Colonização e desenvolvimento do Oeste de Santa Catarina - aspectos sócio-políticos, econômicos e religiosos. Joaçaba: UNOESC, 1997.

HEINSFELD, Adelar. A questão de Palmas entre Brasil e Argentina e o início da colonização alemã no baixo vale do rio do Peixe. Joaçaba: UNOESC, 1996.

JAEGER, Ervino Eugênio. A terra que eu sonhei. Nova Petrópolis: Editora Amstad, 1998.

JUNGblut, Roque. Documentário Histórico de Porto Novo. São Miguel do Oeste: Arco Îris Gráfica e Editora, 2000. 
KLAUCK, Samuel. Representações da organização familiar e comunitária dos teutobrasileiros católicos do Rio Grande do Sul a partir da revista St. Paulus-Blatt (1912 a 1934). História: debates e tendências, Passo Fundo, v. 14, n. 1, jan./jun. 2014, p. 141-152.

LEVI, Giovanni. O trabalho do historiador: pesquisar, resumir, comunicar. Revista Tempo, vol. 20, 2014, p. 1-20.

NEUMANN, Rosane Márcia. Quem nasce no Brasil, é brasileiro ou traidor! As colônias germânicas e a campanha de nacionalização. São Leopoldo, RS: Dissertação de Mestrado em História do Programa de Pós-Graduação em História da Universidade do Vale do Rio dos Sinos - UNISINOS, 2003.

NODARI, Eunice Sueli. A dor do esquecimento: as marcas da ditadura Vargas no Oeste de Santa Catarina. Florianópolis: História Oral, v. 12, n. 1-2, p. 157-176, jan.dez., 2009.

RABUSKE, Arthur; RAMBO, Arthur Blásio. Pe. J. E. Rick, Sj: Cientista, colonizador, apóstolo social, professor. São Leopoldo: Unisinos, 2004.

RAMBO, Arthur Blásio. Somando forças: o projeto social dos jesuítas do sul do Brasil. São Leopoldo: UNISINOS, 2011.

ROCHE, Jean. A colonização alemã e o Rio Grande do Sul. Tradução Emery Ruas. Porto Alegre: Editora Globo, 1969.

ROHDE, Maria W. Espírito Pioneiro: a herança dos antepassados. Itapiranga: Gráfica e Editora Porto Novo, 2011.

TRAMONTINI, Marcos Justo. A organização social dos imigrantes. A colônia de São Leopoldo na fase pioneira (1824-1850). São Leopoldo: Editora Unisinos, 2003.

WERLE, André Carlos. Porto Novo: o reino jesuítico germânico no oeste de Santa Catarina. Curitiba: CRV, 2011.

WITT, Marcos Antônio. Em busca de um lugar ao sol: estratégias políticas, imigração alemã, Rio Grande do Sul, Século XIX. São Leopoldo: Oikos, 2008.

\section{FONTES PRIMÁRIAS:}

ARQUIVO HISTÓRICO DA PARÓQUIA SÃO PEDRO CANÍSIO. Livro Tombo da Paróquia. Itapiranga, SC.

JORNAL Expressão. Edição 337. 